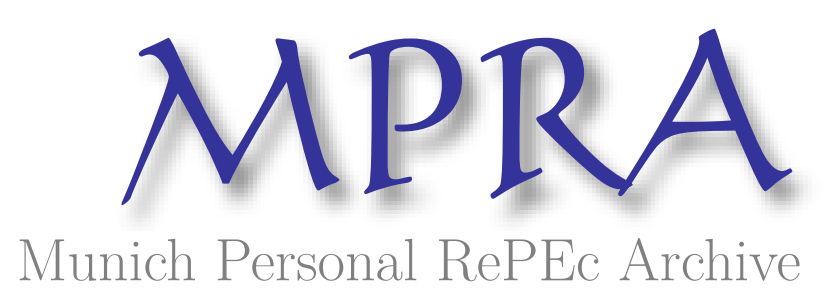

\title{
Interaction of Eurasian and International Financial Institutions
}

Vinokurov, Evgeny

Eurasian Development Bank

2020

Online at https://mpra.ub.uni-muenchen.de/98971/

MPRA Paper No. 98971, posted 18 Mar 2020 22:41 UTC 


\title{
Interaction of Eurasian and International Financial Institutions
}

\author{
Evgeny Vinokurov ${ }^{1}$
}

\footnotetext{
${ }^{1}$ Evgeny Vinokurov, Chief Economist, Eurasian Fund for Stabilization and Development, EDB. Address: Eurasian Fund for Stabilization and Development, EDB, $1^{\text {st }}$ Zachatyevsky Lane 3b1, Moscow 119034, Russia. Tel. +7-962-7067486, e-mail: vinokurov_ey@eabr.org and evgeny@vinokurov.info. The author writes in his personal capacity. The conclusions and interpretation of the facts do not reflect the official position of the EDB, the EFSD, and their governing bodies.
} 


\begin{abstract}
:
The paper handles two Eurasian international financial institutions, the Eurasian Development Bank (EDB) and the Eurasian Fund for Stabilization and Development (EFSD), focusing on the modalities of interaction with their international counterparts, including international financial organization and multilateral development banks. We attempt to explain the reasons behind the choice of partners, modalities of interactions, underlying incentives and constraints, and varying dynamics of these two entities. For the EDB, international interaction has to do primarily with the multilateral development banks. For the EFSD, the layout is substantially more complex, as the fund positions itself as an inherent part of the Global Financial Safety Net. The paper eliminates gaps in understanding the modalities and dynamics of the EDB and EFSD's interaction with their counterparts among international financial institutions (IFIs) and provides an explanation for the institutional logic which manifests itself in these modalities and dynamics. It covers the following questions: What are the reasons behind varying dynamics of international interactions for both institutions? What conditions the choice of institutions to cooperate with? What is the relation between competition and complementarity in these interactions?
\end{abstract}

Keywords: international financial institutions, regional financing arrangements, multilateral development banks, development financing, international organization, global financial architecture, Global Financial Safety Net, Eurasian Development Bank, Eurasian Fund for Stabilization and Development.

JEL codes: F32, F33, F34, G01, H87. 


\section{Introduction}

This paper considers two Eurasian international financial institutions, the Eurasian Development Bank (EDB, the Bank) and the Eurasian Fund for Stabilization and Development (EFSD, the Fund), focusing on the modalities of interaction with their international counterparts. We attempt to explain the reasons behind the choice of partners, modalities of interactions, and varying dynamics.

The purpose of this paper is, first, to eliminate gaps in understanding the modalities and dynamics of the EDB and EFSD's interaction with their counterparts among international financial institutions (IFIs), and, second, to provide an adequate explanation for the institutional logic which manifests itself in these modalities and dynamics. The questions to answer in this paper are the following: What are the reasons behind varying dynamics of international interactions for both institutions? What conditions the choice of institutions to cooperate with (reasons behind the choice of partners)? What is the relation between competition and complementarity in these interactions? In addition, do the Eurasian IFIs challenge or complement the global financial architecture?

Both Eurasian IFIs are young (EDB exists since 2006, and EFSD since 2009) but their importance for their six member states (Armenia, Belarus, Kazakhstan, Kyrgyzstan, Russia, and Tajikistan) can already be felt. Over 13 years, EDB has financed projects in excess of $\$ 8 \mathrm{bln}$. EFSD's net flows into its four borrowings countries are, in turn, comparable to those of the World Bank. Practical importance of both inter-state institutions goes beyond project financing as they act as liaisons, catalysts, and supporters of various inter-state processes and initiatives.

Before delving into the empirics of IFI interaction, we lay down what forms of cooperation and competition between the Eurasian and international IFIs can exist in principle. As concerns cooperation, it can exist in the following forms and domains. First, joint financing of projects (parallel financing, contract financing, syndicates, etc.) would represent cooperation in the main business of multilateral development institutions. Second, joint programming could be relevant for providing policy-based loans. While being active in a country-borrower, such organizations as the IMF, the World Bank (WB), the Asian Development Bank (ADB) and the EFSD could agree on a consolidated policy framework, or at least conduct consultations on its substance. Third, as IFIs are generally research-heavy institutions, joint research projects are possible (and often represent the most politically acceptable form of cooperation in periods of rising tension). Fourth, the Eurasian IFIs could adopt 'best practices' of their international counterparts with regards to their regulations and institution-building.

Various forms and domains of competition are also perfectly possible. They mirror the cooperation opportunities. First, the IFIs may not only cooperate on loans, they can also engage in outright competition for the best projects (well-prepared and financially viable infrastructure projects are actually scarce). In addition, Eurasian IFIs may undermine the major IFIs' policy objectives: an example would be a Eurasian IFI providing financing for coal-based power plants while international donors make a concerted push to support renewable sources of electric power. Second, as concerns joint programming of policy-based loans, IFIs may engage in undermining each other by offering better terms to the borrowing country (that is, less conditionality for the loans). Then the country in question may engage in facility shopping to obtain a less stringent program. Third, the IFIs may compete in their research activities, pouring resources into the same issues and pushing for their own explanations (this may actually be a good thing from the point of view of providing research as a public good).

A few caveats. First, we do not cover such multilateral development banks as the Black Sea Trade and Development Bank (BSTDB), International Investment Bank (IIB), or International Bank for Economic Co-Operation (IBEC). The only reason behind the focus on the EDB and EFSD is that 
they are currently constrained to working in the post-Soviet space and, largely, in members of the Eurasian Economic Union (EAEU), with the single addition of Tajikistan. At the same time, the former three banks, reflecting their history, have a substantially larger membership, extending to many countries of Europe, Asia and even beyond. Second, while the EDB is a full-fledged international financial organization with the respective legal status, the EFSD is essentially a trust fund administered by the EDB. While all principal decisions are taken by its own governing bodies (most importantly, the Fund's Council at the level of the ministers of finance) and its Project Unit possesses a semi-autonomous status within the EDB, the absence of a 'legal' entity is a fact. Hence, while describing the EFSD's modalities of operation, we use the term 'institution' and not 'organization'. Third, while focusing on IFIs, we also very briefly cover interaction with nonfinancial international organizations for the sake of a complete picture. Fourth, a disclaimer is due: EDB and EFSD are also 'international' financial institutions - we use them 'Eurasian' throughout the paper for the sake of differentiating them from their international counterparts.

This paper comprises five sections. The first one is an introduction. In Section 2, we provide a stylized description of these two relatively unknown Eurasian financial institutions, followed by a literature review. Section 3 provides a descriptive and comparative analysis of the modalities of the EDB and EFSD's interaction with the multilateral development banks, then within the GFSN, including the IMF and various RFAs, and, finally, cooperation in research. In Section 4, we make an attempt to systematically explain the overall logic of the Eurasian financial institutions' interaction with their international counterparts, covering the underlying incentives, institutional constraints, resulting modalities, and varying dynamics. Section 5 provides conclusions.

\section{Stylized Description and Literature Review}

The EDB is an international financial institution established to promote economic growth in its member states, extend trade and economic ties among them, and support integration through investment. Russia and Kazakhstan established the Bank in 2006. Armenia and Tajikistan joined in 2009, Belarus in 2010, and Kyrgyzstan in 2011. The Bank's charter capital totals $\$ 7$ billion, including $\$ 1.5$ billion of paid-in capital and $\$ 5.5$ billion of callable capital. Its investment portfolio, as of September $1^{\text {st }}, 2019$, reached $\$ 3.9$ bln, with a concentration in electric power and distribution, transport, the financial sector, and mining.

The Bank has the status of an international organization. As an entity regulated by international law, the EDB has international legal status and enjoys the rights of a legal entity on the territory of its member states. As early as 2007, the Bank acquired the status of observer at the UN General Assembly, UNCTAD Trade and Development Board, and at the Eurasian Group on Combating Money Laundering and the Financing of Terrorism (EAG).

The Eurasian Fund for Stabilization and Development, initially called the EurAsEC Anti-Crisis Fund, is an RFA established in 2009 by Armenia, Belarus, Kazakhstan, the Kyrgyz Republic, Russia and Tajikistan. Since the Fund's establishment, total initial contributions and net profit have reached $\$ 9.1$ billion. Initial contributions of the member states to the Fund amounted to $\$ 8.513$ billion. $10 \%$ of the initial contributions were made to the Fund's account in the form of cash, and the remaining $90 \%$ were made in the form of simple, non-circulating and non-interestbearing promissory notes of the member states. The EFSD is the regional layer of the GFSN which supports member countries' fiscal position and balance of payments (BoP), as well as their national investment projects. The latter is a unique feature of the Fund among other similar institutions. The EFSD has made a material contribution to the external financing of four recipient states Armenia, Belarus, Kyrgyzstan, and Tajikistan. During 2010-2018, the Fund provided about onefifth of all the funding they received from all IFIs, on a net basis. The net flows from the EFSD to these four countries are comparable to the WB's financing $(0.28 \%$ of the total GDP of the four borrowing countries from the EFSD and $0.27 \%$ from the WB for 2010-2017) (Vinokurov, Efimov, Levenkov, 2019). 
Unlike the EDB, the EFSD is not an organization, but an institution. It is legally a fund belonging to six member states and administered by the EDB. It has its own governing bodies, with all major decisions taken by the Council at the level of ministers of finance. The EFSD Project Unit within the EDB enjoys a semi-autonomous status. Nevertheless, it is not a de-jure international financial organization.

\section{Box 1. EDB at a Glance}

Date of establishment: 12 January 2006

Bank's capital: $\$ 1.5$ billion paid-in $+\$ 5.5$ billion on-call capital

Cumulative investment portfolio (including completed projects): $\$ 8.198$ billion

Current investment portfolio: \$3.896 billion*

At present, the EDB is financing 96 investment projects in six member states
Member states
Republic of Armenia
Republic of Belarus
Republic of Kazakhstan
Kyrgyz Republic
Russian Federation
Republic of Tajikistan

Largest shares in investment portfolio:

$>$ electric power;

$>$ financial sector;

$>$ transport;

$>$ mining.

Source: EDB website www.eabr.org, as of 01.09.2019

*as of 31.12.2018. Source: EDB (2019)

\section{Box 2. EFSD at a Glance}

\author{
Date of establishment: 9 June 2009 \\ Fund's total financial resources*: $\$ 9.1$ billion \\ The EFSD does not raise funds in capital markets. \\ Total commitments**: $\$ 5.5$ billion \\ Disbursed: $\$ 4.8$ billion \\ Outstanding $* * *: \$ 3$ billion \\ Source: Vinokurov, Efimov, Levenkov (2019), as of \\ 01.07.2019 \\ Notes: * (a) contributions to the Fund; (b) proceeds from \\ the placement of temporarily idle Fund resources; (c) \\ revenues from the resources provided by the Fund on a \\ refundable basis; $(d)$ donations; ( $e$ ) other income; ** all \\ financial commitments ever approved by the Fund's \\ Council minus cancellations $* * *$ disbursed minus debt \\ repayments
}

\author{
Member states \\ Republic of Armenia \\ Republic of Belarus \\ Republic of Kazakhstan \\ Kyrgyz Republic \\ Russian Federation \\ Republic of Tajikistan
}

Instruments:

$>$ The main tool of the EFSD is budget and BoP support loans to sovereign states.

$>$ Infrastructure investment loans

$>$ Grants for social projects

$>$ Research

All projects and programs are owned by the member countries $=$ only sovereign lending.

The EDB and EFSD share the same membership. The geography of both institutions largely defines their mandate and business lines. To begin with, all national economies show profound 
dependence on Russian economic trends. It happens through various transmission channels from Russia. The impact, both positive and negative, is exerted through a number of transmission channels, including trade flows, flows of direct and portfolio investments, the credit channel, inflation, interest rates, remittances of migrant workers, and economic expectations (Table 1). Remittances stand out as the single most important channel for Kyrgyzstan and Tajikistan, amounting to ca. $30 \%$ of GDP. Secondly, the economies of the EDB and EFSD's region of operations share a dependence on commodity exports, either directly or indirectly. In the former case, the following exports are important: for Russia and Kazakhstan - oil, gas, metals, fertilizers, grain; for the Kyrgyz Republic - gold; for Belarus - potassium and oil refineries. Effectively, this leads to a strong dependence on commodity prices and an increased risk of shocks when there is strong price volatility.

Table 1. Indicators of the Social and Economic Development of EDB and EFSD Member Countries, 2018

\begin{tabular}{|c|c|c|c|c|c|c|c|}
\hline & Armenia & Belarus & $\begin{array}{l}\text { Kazakh- } \\
\text { stan }\end{array}$ & $\begin{array}{l}\text { Kyrgyz } \\
\text { Republic }\end{array}$ & Russia & Tajikistan \\
\hline \multirow{4}{*}{ GDP } & $\begin{array}{l}\text { Nominal } \\
\text { GDP, \$ } \\
\text { billion }\end{array}$ & 12.4 & 59.6 & 172.9 & 8.1 & $1,657.3$ & 7.5 \\
\hline & $\begin{array}{l}\text { GDP at } \\
\text { purchasing- } \\
\text { power } \\
\text { parity, } \$ \\
\text { billion }\end{array}$ & 30.7 & 190.8 & 507.6 & 24.3 & $4,179.6$ & 30.6 \\
\hline & $\begin{array}{l}\text { Nominal } \\
\text { GDP per } \\
\text { capita, } \$\end{array}$ & $4,188.1$ & $6,020.0$ & $9,977.4$ & $1,254.1$ & $10,950.5$ & 807.1 \\
\hline & $\begin{array}{l}\text { GDP growth } \\
\text { rate, average } \\
\text { for } 2010 \text { - } \\
2018, \%\end{array}$ & 4.1 & 1.9 & 4.5 & 4.1 & 1.9 & 7.0 \\
\hline \multicolumn{2}{|c|}{ Population, million } & 2.9 & 9.4 & 18.4 & 6.4 & 146.9 & 8.9 \\
\hline \multicolumn{2}{|c|}{$\begin{array}{l}\text { Foreign trade } \\
\text { turnover, } \$ \text { billion }\end{array}$} & 7.4 & 72.1 & 93.5 & 6.7 & 693.1 & 4.2 \\
\hline
\end{tabular}

Source: IMF, World Bank, national statistical offices, EFSD calculations.

Both Eurasian financial institutions have represented an almost complete terra incognita in academic and non-academic literature up until very recently. The situation has been remedied somewhat over the last two years. Primary official data and information can be sourced from the EDB Annual Report, which contains a section on the EFSD (EDB, 2019), and from the EDB website, which contains the EFSD sub-domain as well. ${ }^{2}$ The latter, providing only scarce information until 2018, has been revamped during 2019, now offering more information on corporate governance, projects, various procedural issues, research, and international cooperation.

\footnotetext{
${ }^{2}$ The EDB website and the EFSD sub-domain are https://eabr.org/en/ and https://efsd.eabr.org/en/, respectively.
} 
In addition, when the Fund launched its Working Paper Series, the first two papers specifically targeted the issue of the lack of analysis on EFSD activities. Vinokurov, Efimov, and Levenkov (2019) provide analysis on the role and place of the Fund within the GFSN. Their analysis includes the positioning of the EFSD member states vis-à-vis the Fund, a detailed analysis of operations (both budget support and infrastructure investment), international cooperation, research, macroeconomic expertise, and various policy-related issues concerning institution-building. Ulatov, Pisareva, and Levenkov (2019) focus on the 'stabilization vs development' dilemma in the mandate and operation of RFAs and of the EFSD specifically. The latter paper stems from multilateral cooperation with other RFAs and incorporates their experience and views into the analysis. These papers were preceded by Scheubel and Stracca (2016) (later on it appeared in an academic format as Scheubel and Stracca, 2019) and the IMF (2017), which represent a stocktaking by the European Central Bank (ECB) and IMF, respectively. It is also necessary to mention a joint paper by all RFAs, which helped place the EFSD within the more general international landscape (RFA Joint Staff, 2018). The IRC Taskforce on IMF Issues (2018) also takes note of the EFSD in its stocktaking.

Within academic literature, Fritz and Mühlich (2019) stands out. That paper provides an analysis of the RFAs' place in the GFSN, taking two RFAs, the Arab Monetary Fund and the EFSD, as case studies. The issue of how the RFAs manage their main task, the provision of liquidity to their member states in need, is central to the paper. The authors conclude that intra-regional asymmetries play a contradictory role: while the participation of large economies leverages liquidity provision, it simultaneously creates difficulties for the governance of the RFA in question. In addition, Vinokurov has placed both institutions within the general analysis of the Eurasian institutions (the EDB in Vinokurov 2018: 57-61 and EFSD in ibid: 61-64). The EDB is sometimes mentioned within the analysis of economic and institutional integration in various regional contexts (e.g. Pomfret, 2009). Also, Lissovolik and Vinokurov's largely normative paper proposes both Eurasian financial institutions as building blocks, among other IFIs, for developing a more advanced economic and financial cooperation within BRICS and BRICS+ (Lissovolik, Vinokurov, 2019). At the same time, there are no papers on the issue of international cooperation of the Eurasian financial institutions with the IFIs.

\section{Modalities of EDB and EFSD interaction with International Financial Organizations}

Within this section, we intend to analyze the modalities of the EDB and EFSD's interaction with the IFIs in a systematic manner. We divide the interaction processes into three pillars: interaction with multilateral development banks (which, most importantly, takes part within the respective investment portfolio), interaction within the GFSN, which takes place in both IMF and RFAs, and cooperation in research.

\section{Modalities of Interaction with Multilateral Development Banks}

The EDB pursues its cooperation with MDBs, aiming at expanding its capabilities in financing joint projects. Since other MDBs are primarily interested in infrastructure, various infrastructure sectors are at the center of this cooperation.

In 2017, the EDB and the New Development Bank (NDB, also colloquially known as 'BRICS Bank') signed a $\$ 50$ million loan agreement. The EDB used proceeds of the loan to finance the construction of two small hydroelectric power plants, Beloporozhskaya HPPs 1 and 2 in the Republic of Karelia in Russia. Essentially, under this scheme the EDB channeled NDB money to the project while itself taking on the currency risk. In September 2019, the NDB approved allocating \$300 million for the EDB to be used for financing various green energy projects in 
Russia (wind, solar, and small hydro). ${ }^{3}$ The sum is substantial which makes the New Development Bank EDB's most important partner among IFIs.

In 2019, the EDB has signed a Memorandum of Understanding with the Asian Infrastructure Investment Bank (AIIB). This memorandum has yet to materialize at the level of investment projects.

To complete the picture, the EDB is a member of the Multilateral Financial Institutions' Working Group on Environment and Social Standards, the Expert Group for PPP Mechanism Development within the EAEU of the EEC Board's Advisory Committee for Entrepreneurship, the Global Infrastructure Facility (GIF) Advisory Council, and Global Infrastructure Connectivity Alliance (GICA). The EDB holds observer status at the UN General Assembly, EAG, UNCTAD, and the IIB.

Generally, the largest MDBs (such as the WB and ADB) require a sustainable macroeconomic policy as a pre-condition for policy-based financing and budget support. This requires the use of the IMF's informed assessment of the macroeconomic context (IRC Taskforce on IMF Issues, 2018: 34). The EDB does not require such an assessment due to the absence of policy-based financing and budget support among its investment instruments. Hence, the EDB's cooperation with the IMF is close to non-existent.

The cost of financing acts as a constraint for the EDB's involvement with the MDBs. The Bank has a BBB/A-2 rating from Standard and Poor's and Baal from Moody's. Thus, effectively, the Bank enjoys credit ratings at the level of Russia and Kazakhstan. Nevertheless, this translates into an elevated cost of attracting capital in the form of bonds or commercial loans. As a bank, the EDB channels the cost of its financing to its projects (granted, it can also use its capital to a limited extent). Most other MDBs, at least the largest ones such as the WB, ADB, AIIB, etc., enjoy credit ratings at the highest or very high levels (AA or higher), which allows them to provide financing on highly concessional terms.

Let us now turn to the EFSD. Along with budget and BoP support for the member states, the Fund introduced a second type of loan in the form of infrastructure investment loans in 2014. Investment loans are provided to the EFSD member states for large national investment projects in, mostly, hydropower and automobile transportation, but also agriculture and irrigation. As the Fund's institutional capacity is still very small, over recent years it has increasingly relied on its institutional partners among the MDBs, namely the WB and the ADB, to structure and implement projects at the operational level. Thus, cooperation with the MDBs serves the goal of opening new project opportunities under the modes of parallel and contractual co-financing. As of mid-2019, it is engaged in co-financing development projects with the ADB in the Kyrgyz Republic (Toktogul HPP, Uch-Kurgan HPP, and the Bishkek-Osh road) and Armenia (the North-South Road Transport Corridor), and with the WB in Tajikistan (Nurek HPP) and also Armenia (modernization of the irrigation system). The AIIB is also a partner in the Nurek HPP project.

For example, in 2015, the EFSD joined the project to revamp the Toktogul HPP, providing an amount of \$100 million. The ADB is providing \$110 million in co-financing. The project will comprehensively modernize the hydropower plant, with the following results: increased reliability and stability of the power supply and a greater supply of electricity to the population; increased energy security and sustainability of the country's energy system; growth of the Kyrgyz Republic's export potential through the export of surplus electricity to other EFSD members; an improved balance of payments; and a decrease in the severity of electricity shortages in winter time.

\footnotetext{
${ }^{3}$ https://www.ndb.int/press_release/ndb-board-directors-convenes-21st-meeting-shanghai-approves-projects-loansaggregating-usd-1-4-bln/, accessed November 19 ${ }^{\text {th }}, 2019$.
} 
Thus, the total scope of EFSD cooperation with the leading MDBs is very substantial and covers the majority of the EFSD's infrastructure investment loans.

The cost of financing, which acts as a power constraint for the EDB's cooperation with the MDBs, is not relevant for the EFSD since the latter, being a fund, does not depend on capital markets for financing. At the same time, the EFSD operates under a number of constraints not relevant for the Bank. To begin with, it finances large national projects by providing funds directly to the respective sovereign state. Thus, private projects are explicitly excluded. This limitation is not a particularly powerful one since in low-income countries (in contrast to other income brackets) there are virtually no private projects in basic infrastructure. A much more substantial constraint is that the EFSD finances only basic infrastructure under its mandate and strategy. Thus, its investment may go only to power, transport and agriculture, coupled with irrigation projects.

These institutional constraints certainly make sense since they help guarantee that the Fund's means are not squandered on projects of lesser importance for the national economies. As explained in Section 2, the EFSD's financial resources are finite, as it does not raise funds in capital markets.

Apart from launching new project opportunities, the EFSD pursues other objectives in cooperating with the MDBs. The Fund's potential and the quality of its macroeconomic expertise are enhanced through regular consultations during country missions, dialogue among macro- and sectoral economists, mutual training programs and internships, as well as the preparation of joint research papers. A worthy objective is to coordinate actions in the Fund's member countries, including joint implementation of programs and projects. Partnership with the IMF is especially important for the EFSD, considering that IMF programs and criteria have a significant overlap with the Fund's priorities and principles regarding budget support loans. Partnerships with the WB and the ADB are no less important for the EFSD, and these are developing in a number of areas, primarily through joint infrastructure projects. Finally, the Fund aims to learn from best practices to harmonize standards and environmental and social responsibility policies with the regulations of leading IFIs.

\section{Modalities of EFSD Interaction within the Global Financial Safety Net: Budget and Balance of Payments Support, Cooperation with RFAs}

The GFSN is defined as the set of financial resources and institutional arrangements that provide a backstop during a financial or economic crisis. The safety net is a form of insurance against financial crises (following Hawkins et al., 2014:2; Scheubel and Stracca, 2016). The GFSN has three main objectives: (i) to provide insurance for countries against a crisis; (ii) to supply financing when crises hit; and (iii) to incentivize sound macroeconomic policies (IMF, 2016). This is not an organization but rather a network of national and supranational instruments aiming to achieve the goals mentioned above. The GFSN comprises international reserves, central bank bilateral swap arrangements (BSAs), RFAs, and the IMF. Among these layers, the significance of RFAs for small economies has been systemically underestimated (Fritz and Mühlich, 2019). Small economies, as a rule, do not have access to BSAs, and their own reserves are too small to successfully deal with a crisis without external assistance.

The global financial crisis of 2008 made the need to strengthen multilateral cooperation and create a more coherent and effective GFSN very clear. Overall, the GFSN has grown considerably over the decade since the global financial crisis of 2008-2009. The data shows that an impressive amount of short-term liquidity has been available through the GFSN - \$12.8 trillion, which is about 15 percent of world GDP (Kring and Gallagher, 2019).

During the decade after the global crisis, the regional component of the GFSN increased due to the "new" RFAs by $\$ 1.1$ trillion, and coverage expanded to 43 countries. The RFA "family" 
currently includes eight arrangements: the Arab Monetary Fund (AMF), the BRICS Contingent Reserve Arrangement (BRICS CRA), the Chiang Mai Initiative Multilateralization (CMIM), the EFSD, the European Union Balance of Payments Mechanism (EU-BoP), the European Financial Stability Mechanism, the European Stabilization Mechanism (ESM), and the Latin American Reserve Fund (FLAR). The EFSD was among those RFAs established in the aftermath of the global financial crisis. The EFSD sees itself as an integral part of the GFSN and a key mechanism for maintaining macroeconomic stability in its region of operations.

In turn, RFAs have developed a collaborative approach that offers a certain level of formalization of relations with the IMF in such areas as institutional capacity building, information sharing, and training. RFAs have generally supported the IMF's approach, which can be considered the starting point in the creation of a regulatory framework for a system of interaction between the RFAs and the IMF (RFA Joint Staff, 2018).

Since 2018, as part of its institutional overhaul, the Fund has begun to pursue actively the institutionalization of its cooperation with the IFIs. In IFI practice, this is normally structured through bilateral memoranda of understanding. However, as it turns out, IFIs, as a rule, can only sign memoranda of understanding with organizations that enjoy the status of an international organization. This hindrance has been partially overcome through agreeing on and exchanging letters of intent covering various facets of cooperation (exchange of information, secondments, joint public events, capacity development, etc.). The EFSD exchanged such letters of intent with the IMF in October 2019. An exchange of letters is also in the making with the European Stability Mechanism (as of November 2019). ${ }^{4}$ Thus, in practice, the absence of the status of a full-fledged international organization is a substantial, but surmountable, limitation to international cooperation.

In reality, a more substantial limitation is the mundane issue of understaffing. As of end-2019, the whole Institutional Cooperation Unit's headcount was only one person (the respective head of unit was hired in summer 2019).

To sum up, the EFSD pursues active cooperation with IFIs within the GFSN network. Eager to raise its operational capacity and expertise, the fund has found itself on a steep learning curve, learning from international financial institutions since entering a phase of internal reform. Its priorities are participation in strengthening and developing a network of partnerships on a global level (IMF, WB), regional level (RFAs), and country level (donor clubs). The Fund works with donor clubs in three member states: Kyrgyz Republic (Coordinating Council for Development Partners), Tajikistan (Coordinating Council for Development), and Armenia (Coordination Conference). EFSD representatives participate in high-level conferences of RFAs and the IMF, as well as in RFA Research Seminars. Such conferences and events are an important platform for the development and strengthening of the GFSN.

An important issue is coordination of actions in the Fund's member countries, including joint implementation of programs and projects. Partnership with the IMF is important in this regard, considering that IMF programs and criteria have a significant overlap with the Fund's priorities and principles regarding budget support loans. The partnership between the IMF and the EFSD functions through informal consultations on macroeconomic policy and reforms that were supported by EFSD programs. To avoid repetitive or contradictory macroeconomic recommendations, the EFSD has concentrated on structural reforms when there was an active IMF programme (such as the programme in Armenia in 2015-2017). Considering that the IMF is

\footnotetext{
${ }^{4}$ https://efsd.eabr.org/en/press-center/news/acting-executive-director-of-the-efsd-project-block-and-
} director-of-the-imf-strategy-policy-and-revi/, accessed November $19^{\text {th }}, 2019$. 
increasingly involved in issues of structural transformation, the EFSD also consults with it on this matter.

In 2019, an EFSD staff member took part in the official IMF technical assistance mission for the first time. More specifically, a staff member of the EFSD Chief Economist Group joined IMF experts in their mission to the Zambian Central Bank with the purpose of introducing nowcasting and structural models to the central bank's modelling apparatus. Such exercises are viewed not only at face value (useful technical assistance to the given country) but also as cooperation between two institutions leading to denser horizontal connections and, above all, capacity building as relates to the EFSD's institutional capacity for future own technical assistance to its member states.

In addition, the cooperation with the IMF and such RFAs as the ESM and AMRO helps the Fund develop its macroeconomic expertise through regular consultations during country missions, dialogue among macro- and sectoral economists, mutual training programs and internships, as well as the implementation of joint research programs.

\section{Cooperation in Research}

Many, or even most, IFIs (in particular, the WB and IMF) are research-heavy institutions. The EDB and EFSD are no exception in this regard. A portion of their research activities is based on cooperation with international partners. Let us begin with the EDB. Largely, EDB research either is carried out in-house or involves experts from research institutions of the member states. However, there have been a few cases of cooperation with an IFI. For instance, a joint booklet "Central Asia Development in 3-D", combining WB and EDB expertise, was published in 2009 (WB, EDB, 2009). It merged earlier WB findings expressed in its Reshaping Economic Geography Report with the EDB's findings from its industry reports on electric power and transportation. In 2014, a joint WB-EDB project on pension mobility (EDB Centre for Integration Studies, 2014) was very successful as it effectively led to the establishment of an international working group under the auspices of national pension funds. The research focused on the migrant receiving countries (Russia, Kazakhstan, Belarus) and the sending countries (Kyrgyzstan, Tajikistan, Armenia). It laid on the table a policy proposal for establishing a common pension space in the EAEU based on the principle of proportional pension accrual. This envisaged the establishment of a system to record labor migration and the length of service of migrant workers in different countries, and to ensure communication and offsets between pension funds in the region's countries. The 2019 EAEU agreement on the mobility of pensions has implemented this proposal.

The EFSD, under its ongoing institutional overhaul, prioritizes cooperation with the IFIs, which also covers cooperation in research. ${ }^{5}$ The Fund strives to build up its own analytical capacity to improve the quality of its lending, its public analysis in the Fund's area of specialization, and its further provision of technical assistance to member states in the research domain. The second aim is to achieve a state-of-the-art level of macroeconomic modelling, which must be adapted to the specifics of the countries involved and targets. One of its central components is debt sustainability analysis (DSA) based on joint WB-IMF methodology. To build and operationalize the DSA models, the Fund pursues closer cooperation with the IMF and the ESM. The letter of intent (cited above) signed with the IMF also contains references to consultations on macroeconomic modelling.

The EFSD plans to create a high-quality series of publications, including EFSD Working Papers, reports and individual publications. Within this task, the Fund pursues closer cooperation with the IFIs. In 2018, six RFAs drafted a joint position paper on relations with the IMF (Joint RFA Staff, 2018). EFSD staff took part in this publication. In 2019, as intra-RFA cooperation grew more

\footnotetext{
${ }^{5}$ https://efsd.eabr.org/en/analytics/
} 
intense, the EFSD took part in six joint research tracks with fellow RFAs. In one of them, the Fund took the lead, which eventually led to a joint discussion paper published within the EFSD Working Paper Series (Ulatov, Pisareva, Levenkov, 2019).

Finally, in 2019 the EFSD has committed - with approval by fellow RFAs - to host in 2020 the yearly RFA Research Seminar and welcome staff of the European Stabilization Mechanism, the Latin American Reserve Fund, AMRO, Arab Monetary Fund, as well as delegations from the European Commission, IMF, ECB etc., in Moscow. The yearly RFA Research Seminar is a highlevel event for top management covering such issues as macroeconomic diagnostics, state-of-theart methodology of macroeconomic modelling, etc.

To sum up, both institutions have cases of joint research with IFIs. However, while the EDB's cooperation happens on a case-by-case basis, the EFSD, as part of its institution building, views research cooperation with the IFIs as its systemic priority and is explicitly working on implementing a systematic approach in this regard.

\section{Explaining the Interaction of the Eurasian and International Financial Institutions}

In the introduction, we laid down the modalities of cooperation and competition of the Eurasian and international IFIs which can exist in principle. Briefly, both cooperation and competition may exist in various forms in financing activities, the programming of policy-based loans (that is, requirements for governments that condition the provision of budget support loans), in research, and aligning regulatory frameworks. In Section 2 and, in particular, in Section 3, we described in detail what happens in practice. In this section, we intend to provide an explanatory framework for IFIs interaction, its modalities, specifics, and constraints. Let us remind ourselves of several questions we are particularly interested in answering: What are the reasons behind varying dynamics of international interactions for both institutions? What conditions the choice of institutions to cooperate with (reasons behind the choice of partners)? What is the relation between competition and complementarity in these interactions?

\section{The modalities of interaction of the Eurasian and international financial institutions are} defined by their mandates, strategic priorities, and instrument mix.

The dependence of the modalities of interaction with international counterparts in the respective legal mandates and instruments is obvious. Nevertheless, our framework cannot omit them because of its explanatory power.

For example, the EDB is in the business of providing loans to commercial entities. It is not required to prioritize sustainability issues in its lending policies. Generally, the largest MDBs (such as the $\mathrm{WB}$ and $\mathrm{ADB}$ ) require a sustainable macroeconomic policy as a pre-condition for policy-based financing and budget support. This requires the use of the IMF's informed assessment of the macroeconomic context (IRC Taskforce on IMF Issues, 2018: 34). The EDB does not require such an assessment due to the absence of policy-based financing and budget support among its investment instruments. Hence, EDB cooperation with the IMF is close to non-existent. The EFSD, by contrast, is in the business of providing sovereign loans, in particular, policy-based ones. In fact, $90 \%$ of its current portfolio is composed of five sovereign policy-based loans (budget and $\mathrm{BoP}$ support). Since budget and BoP support are its main instruments, coordination and complementarity with the IMF, WB, and ADB come naturally (all these organizations provide budget support to their eligible member states).

The second EFSD tool is infrastructure lending. The fund shares this instrument with many major MDBs. In the context of low-income economies, IFIs handle much work on constructing and reviving major infrastructure - power plants, roads, bridges, airports, and irrigation facilities. That is only possible with the help of massive concessional lending (with a duration of 20-40 years and 
interest rates not exceeding $2 \%$, usually less). Such projects are normally very capital-intensive, so that even cash-rich IFIs prefer to share the financial burden and risks. That lays the ground for the EFSD's joint financing of projects under the guidance of major MDBs.

The experience in research cooperation of two institutions with their international counterparts is instructive in relation to strategic priorities and mandates. The EFSD demonstrates better trends in that respect. As part of its institutional overhaul in 2018, the Fund prioritized research cooperation with IFIs. An already existing cooperation framework with RFAs helped. Already in October 2018, six RFAs published a joint position paper on relations with the IMF (Joint RFA Staff, 2018), with EFSD staff members as co-authors. A year later, the EFSD has taken the lead role in one of the joint research tracks with a fellow RFA, resulting in a discussion paper. These activities - and the prioritization thereof - are a consequence of the strategic understanding of the EFSD's place within the GFSN and the shareholders' acknowledgement of the importance of close dialogue with other IFIs.

\section{The modalities of interaction of the Eurasian IFIs are defined/constrained by their competitive position relative to IFIs.}

A competitive position of a financial institution critically depends on the cost of financing. Banks (any banks, both development and commercial ones) get funding in the capital markets and then pass resources to their borrowers with an appropriate profit margin. Should the cost of funding be elevated, the bank would be in an inferior competitive position. This is exactly the case with the EDB. The cost of financing acts as a constraint for the EDB's involvement with the MDBs. The Bank has a BBB/A-2 rating from Standard and Poor's and Baal from Moody's. Thus, effectively, the Bank enjoys credit ratings at the level of its most economically advanced shareholders, Russia and Kazakhstan. Nevertheless, this translates into an elevated cost of attracting capital in the form of bonds or commercial loans. As a bank, the EDB channels the cost of its financing to its projects (granted, it can also use its capital to a limited extent). Most other MDBs, at least the largest ones such as the WB, ADB, AIIB, etc., enjoy a credit rating at the highest or very high levels (AA or higher), which allows them to provide financing on highly concessional terms. This is a major explanation of why we witness practically no joint projects with the IFIs.

The EFSD, by contrast, does not face the same constraint. First, it is a fund, not a bank. That means that it utilizes its 'capital' (legally speaking, financial resources provided by member states) to provide sovereign loans. Second, all its loans (unlikely in the EDB case) have a non-commercial character - the EFSD is in the business of providing concessional loans to sovereign states. Both the terms of budget support loans and infrastructure investment loans ('financial' and 'investment' loans in internal jargon) roughly equal those provided by the IMF, the $\mathrm{WB}$, ADB, etc. This opens a window of opportunity for joint financing, which is exactly the case with the EFSD's cooperation with the WB, ADB and, lately, AIIB in Central Asia and the Caucasus.

3. The modalities of interaction of the Eurasian IFIs are constrained by their institutional capacity and status.

Many constraints are in fact of a purely applied nature. Importantly, the EFSD is heavily constrained by the lack of staff and capacity. Hence, for example, its specific modality of cooperation with the WB and ADB on large infrastructure loans. While the WB and ADB structure complex projects (car roads and hydropower stations), the EFSD acts as a 'project and policytaker', being a de-facto junior partner in joint project financing.

Further, for the EFSD, its lack of international organization status acts as a major constraint (as a reminder, the fund is not an independent international organization but, rather, a trust fund under EDB management with a semi-autonomous project unit and with its own autonomous governing body). The fund may not register with the UN; IFIs may not sign proper memoranda of understanding with it for this very reason, etc. The EDB, on the contrary, enjoys the status of an 
international organization. Thus, as a whole, independent IFI, it does not face this constraint. Therefore, the EDB has gained membership in various international fora - the status of observer at the UN General Assembly, UNCTAD, etc.

4. Interactions of Eurasian and international IFIs represent an interplay of complementarity and competition; 'cut-throat' competition is very unlikely due to the overlapping shareholders.

As we have demonstrated, the EDB's engagement with IFIs is generally limited. However, it features instances of both cooperation and competition. On the former, cooperation with NDB is flourishing. On the latter, one could mention the EDB buying out the EBRD's projects following its exit from Russia.

The EFSD has a more complicated relationship. There is a real threat of facility shopping by states in the case of overlapping membership (whichever institution may provide better terms and less stringent requirements for a balance of payments or a budget support loan). IFIs want to avoid that. In a few instances, IMF-EFSD interaction has been a genuinely cooperative one. For example, to avoid repetitive or contradictory macroeconomic recommendations, the EFSD concentrated on structural reforms in its program in Armenia in 2015-17 since there was an active IMF program. On the other hand, various IFIs have their own priorities and loan portfolios to nurture and take care of. The playing field of concessional sovereign loans is a specific market - but a market, nevertheless.

Both cooperation and competition between the Eurasian financial institutions and their international counterparts are feasible, and, in fact, take place in practice. Having said that, the specific governance structures of the IFIs ensure the absence of outright 'cut-throat' competition between them. Unlike commercial banks, the IFIs have completely or partially coinciding lists of shareholders, which are sovereign member states. For example, all shareholders of both the EDB and EFSD are simultaneously shareholders in the WB, IMF, and the AIIB. Moreover, there is a partial concurrence of shareholders with the EBRD and the ADB. There is an important consequence to that: since the same countries are shareholders, the international and Eurasian financial institutions' objectives and policies may not diverge too much. In fact, they may diverge in some important details, but many of the underlying objectives and policies are bound to be similar.

\section{Political constraints do not pose a major problem for international cooperation at present.}

Given the political tensions between Russia (the majority shareholder of both the EDB and EFSD, with 65 and 88 percent of capital, respectively) and the West, it would be natural to assume that politics imposes huge constraints on the interaction in question. Our analysis demonstrates, however, that this is largely not the case. Certainly, the unfavorable political environment serves as a substantial constraint for some institutions in some cases. For example, the EBRD has been exiting Russia since 2014. Practically no cooperation with this institution exists. There might also be certain reservations on the side of various IFIs, or factions within them, about cooperating closely with Eurasian ones. However, in practice that does not preclude substantial cooperation on projects, policies, or research. It has to do with what we showed above: the IFIs share the same shareholders, which ensures that a passable level of cooperation is being supported if needed. In general, political constraints do not represent a major problem, at least at the present level of international cooperation between Eurasian IFIs and their international counterparts.

\section{Conclusion}

This paper considered two Eurasian international financial institutions, the EDB and the EFSD, and the scope and depth of its institutional cooperation with their international counterparts Eurasian Development Bank (EDB, the Bank) and the Eurasian Fund for Stabilization and 
Development (EFSD, the Fund), focusing on the modalities of interaction with their international counterparts.

It further provided an explanatory framework for the empirical reality. On the modalities of interaction, we suggest the following. First, the modalities of interaction of the Eurasian and international financial institutions are defined by their mandates, strategic priorities, and instrument mix. Second, they are defined/constrained by whether they are internationally competitive in terms of the cost of capital. Third, the modalities of interaction are constrained by the respective institutions' capacity and legal status or absence thereof.

We did not find enough evidence for the hypothesis that the ongoing political tensions posed a major problem for international cooperation among Eurasian and international IFIs so far. On the contrary, the EFSD in particular is increasing its scope and depth of involvement with the IFI reflecting both its strategic view of itself as an inherent part of the Global Financial Safety Net and the objective to team up on the large-scale infrastructure loans to its member states. Further, interactions of Eurasian and international IFIs represent an interplay of complementarity and competition. Generally, 'cut-throat' competition is absent, of which the overlapping membership at the level of sovereign member states is a powerful explanation.

\section{References}

EDB Centre for Integration Studies (2014) Pension Mobility within the EAEU and the CIS. Report no. 24. Joint World Bank - Eurasian Development Bank project. Analytical Summary in English is available at: https://eabr.org/upload/iblock/796/edb_centre_report_24_wb_mirpal_analytical_summary_e ng_1.pdf

EDB (2019) EDB Annual report 2018. EDB: Moscow. Available at: https://eabr.org/upload/iblock/fda/EABR_AR_2018_web_1_.pdf

ESM (2016) The Global Financial Safety Net through the Prism of G20 Summits. ESM: Luxembourg.

Fritz, B., Mühlich L. (2019) Regional Financial Arrangements in the Global Financial Safety Net: The Arab Monetary Fund and the Eurasian Fund for Stabilization and Development. Development and Change, 50(1): 96-121.

Grabel, I. (2019) Continuity, Discontinuity and Incoherence in the Bretton Woods Order: A Hirschmanian Reading. Development and Change, 50(1): 46-71.

Hawkins, A. J., Rahman, and T. Williamson (2014) Is the Global Financial Safety Net at a Tipping Point to Fragmentation? Economic Roundup 2014, Issue 1. Canberra: The Treasury, Australian Government. Available at: https://treasury.gov.au/publication/economic-roundupissue-1-2014/economic-roundup-issue-1/is-the-global-financial-safety-net-at-a-tippingpoint-to-fragmentation/

Henning, C.R. (2019) Regime Complexity and the Institutions of Crisis and Development Finance. Development and Change, 50(1): 24-45.

IMF (2017) Collaboration Between Regional Financing Arrangements and the IMF - Background Paper. IMF Policy Paper.

IMF (2019) World Economic Outlook. Growth Slowdown, Precarious Recovery. April 2019. IMF: Washinton D.C.

Available

at: https://www.imf.org/en/Publications/WEO/Issues/2019/03/28/world-economic-outlook$\underline{\text { april-2019 }}$ 
IRC Taskforce on IMF Issues (2018) Strenthening the Global Financial Safety Net. Moving Relations between the IMF and Regional Financing Arrangements Forward. ECB Occasional Papers Series no 207, March. ECB: Luxembourg.

Kring, W., Gallaher, K. (2019) Strengthening the Foundations? Alternative Institutions for Finance and Development. Development and Change, 50(1): 3-23.

Lissovolik Y., Vinokurov E. (2019) Extending BRICS to BRICS+: Potential for Development Finance, Connectivity, and Financial Stability. Area Development and Policy, 4(2): 117-133.

Pomfret, R. (2009) Regional Integration in Central Asia. Economic Change and Restructuring 42(1): 47-68

RFA Joint Staff (2018) IMF-RFA Collaboration: Motives, State of Play, and Way Forward. A joint RFA staff proposal (ESM, AMF, AMRO, EFSD, EC, FLAR). October.

Scheubel, B. and Stracca, L. (2016) What do we know about the global financial safety net? Rationale, data and possible evolution. European Central Bank Occasional Paper Series \#177, September.

Scheubel, B, and L Stracca (2019) What do we know about the global financial safety net? Rationale, data and possible evolution, Journal of International Money and Finance, forthcoming.

Vinokurov E. (2018) Introduction to the Eurasian Economic Union. London and New York: Palgrave Macmillan.

Vinokurov E., Efimov A., Levenkov A. (2019) The Eurasian Fund for Stabilization and Development: a Regional Financing Arrangement and its Place in the Global Financial Safety Net. EFSD Working Paper no.1. EDB: Moscow. Available at: https://efsd.eabr.org/en/research/working-papers/the-eurasian-fund-for-stabilization-anddevelopment-a-regional-financing-arrangement-and-its-place-i/

Ulatov S., Levenkov A., Pisareva N. (2019) Achieving Stabilization and Development Objectives in a Single Agenda. EFSD Working Paper no. 2. EDB: Moscow. Available at: https://efsd.eabr.org/research/working-papers/

World Bank, Eurasian Development Bank (2009) Central Asia Development in 3-D. World Bank: Washington D.C.; EDB: Almaty. 